\title{
HUBUNGAN TINGKAT PENGETAHUAN SIKAP DAN TINDAKAN PEDAGANG DALAM MENGELOLA SAMPAH DENGAN KEPADATAN LALAT DI PASAR DESA ADAT SEMBUNG TAHUN 2020
}

\author{
Putu Mutiara Ayu ${ }^{1}$, I Wayan Sali ${ }^{2}$, I Ketut Aryana ${ }^{3}$
}

\begin{abstract}
Abstrac Market including public places as a place for interaction. According to the Decree of the Minister of Health of the Republic of Indonesia Number: 519 / Menkes / SK / VI / 2008, traditional markets are markets that mostly sell daily necessities with simple trading practices and do not heed the health rules. The density of flies is an indicator of how poor waste management or poor sanitary conditions are. The purpose of this study is to determine the relationship between the level of knowledge, attitudes, and actions of traders in managing waste with the density of flies in the Sembung Village Market in 2020. This type of research is observational analytic research with all population techniques used as samples and Chi Square test. The number of respondents in this study were 48 traders. The results of this study indicate that respondents have an unfavorable level of knowledge with high fly density (54.2\%). Respondents' attitudes indicate that the attitude of unfavorably high fly density (54.2\%). The respondent's actions were not good with high fly density (56.3\%). The level of density of flies with high categories was more (56.3\%). Statistical test results using the chi square test obtained $p$ value $=0,000<\alpha(0.05)$ which means $\mathrm{Ho}$ is rejected or there is a significant or significant relationship between the level of knowledge, attitudes, and actions with the level of fly density.
\end{abstract}

Keywords: Knowledge, Attitude, Action, Density of Flies

\section{PENDAHULUAN}

Pasar yang sehat dan memenuhi syarat sanitasi salah satunya adalah adanya suatu Pengendalian Vektor Penyakit, beberapa dari macam vektor penyakit yang perlu diperhatikan yaitu lalat. Kepadatan lalat adalah suatu indikator kurang baiknya cara pengelolaan sampah atau rendahnya kondisi sanitasi. Keadaan seperti itu juga dapat mempengaruhi keberadaan lalat di tempat penjualan makanan atau jajanan terbuka yang dijual di pasar. ${ }^{1}$

Salah satu perusahaan daerah yang dikelola oleh Kabupaten Badung yakni Pasar Desa Adat Sembung yang berdiri diatas tanah seluas $2850 \mathrm{~m}^{2}$. Pasar ini merupakan pasar tradisional yang beroperasi setiap harinya mulai dari jam 4 pagi hingga jam 12 siang. 
Kondisi di sekitar pasar tergolong kotor setelah ditingkalkan oleh pedagang terutama di sekitaran pedagang berjualan. Dari survey awal yang dilakukan penulis mengamati masih adanya terlihat sampah, tidak semua pedagang menyediakan tempat pewadahan sampah, serta kurangnya sarana TPS dan tong sampah dari pihak pengelola. Selain itu kurangnya partisipasi pedagang dalam bekerjasama mengatasi masalah pengelolaan sampah di Pasar Desa Adat Sembung. Pasar Desa Adat Sembung ini hanya memiliki satu buah contrainer sampah diangkut sekitar 4 hari sekali, maka dari itu penulis melakukan pemeriksaan di satu titik yakni di dekat contrainer (tempat pembuangan sampah) diperoleh hasil tingkat kepadatan lalat yaitu rata-rata 15,4 (kategori tinggi). Tujuan penelitian untuk mengetahui "Hubungan Tingkat Pengetahuan, Sikap dan Tindakan Pedagang Dalam Mengelola Sampah Dengan Kepadatan Lalat di Pasar Desa Adat Sembung”.

\section{METODE PENELITIAN}

Jenis penelitian ini termasuk penelitian analitik observasional, penelitian observasional yang umum dilaksanakan adalah penelitian metode cross sectional. Dengan sampel yaitu 48 orang pedagang. Jumlah dan besar sampel yang menjadi subyek dalam penelitian ini adalah seluruh pedagang di Pasar Desa Adat Sembung. Pengumpulan data yang dilakukan secara langsung pada objek penelitian. Data ini dikumpulkan menggunakan kuisioner dan observasi untuk mendapatkan hasil penilaian pengetahuan, sikap dan tindakan pedagang membuang sampah serta pengukuran kepadatan lalat di wilayah Pasar Desa Adat Sembung dikumpulkan dengan menggunakan alat fly grill.

\section{HASIL DAN PEMBAHASAN}

A. Hubungan tingkat pengetahuan pedagang dalam mengelola sampah dengan kepadatan lalat

Hasil penelitian terhadap tingkat pengetahuan didapatkan bahwa pedagang yang memiliki tingkat pengetahuan yang kurang baik 
sebagian besar yaitu $54,2 \%$ memiliki kepadatan lalat yang tinggi sedangkan pedagang yang memiliki tingkat pengetahuan yang baik sebagian besar yaitu $22,9 \%$ memiliki kepadatan lalat yang sedang. Kuat lemahnya hubungan dilihat dari koefisien kontingensi C yaitu 0,487 , nilai tersebut menunjukkan hubungan yang sedang antara variabel tingkat pengetahuan dengan kepadatan lalat.

Dilihat dari tingkat pendidikannya, kebanyakan responden pendidikan terakhirnya yakni 28 orang $(58,3 \%)$ berpendidikan terakhir SD, 12 orang $(25,0 \%)$ berpendidikan terakhir SMP dan 8 orang $(16,7 \%)$ perpendidikan terakhir SMA. Menurut penelitian 2 menyatakan bahwa pendidikan yang dikatakan rendah yaitu tingkat SD-SMP, Sosialisasi adalah suatu proses dimana didalamnya terjadi pengambilan peranan. Dalam proses ini sesorang belajar untuk mengetahui peranan yang harus dijalankannya serta peranan yang harus dijalankan orang lain. Pada penelitan ${ }^{3}$ menyatakan Menurut teori dikatakan bahwa sampah yang dibuang pada tempatnya dengan benar dapat memberikan pengaruh yang baik, diantaranya yaitu mengurangi tempat perkembangbiakan serangga atau sumber penyakit, keadaan estetika lingkungan yang bersih menimbulkan semangat dan menurunkan kejadian penyakit menular yang disebabkan oleh sampah B. Hubungan sikap pedagang dalam mengelola sampah dengan kepadatan lalat

Hasil penelitian terhadap sikap pedagang dalam mengelola sampah dengan kepadatan lalat, didapatkan bahwa pedagang yang memiliki sikap yang kurang baik sebagian besar yaitu $54,2 \%$ memiliki kepadatan lalat yang tinggi sedangkan pedagang yang memiliki tingkat pengetahuan yang baik sebagian besar yaitu $25,0 \%$ memiliki kepadatan lalat yang sedang. Kuat lemahnya hubungan dilihat dari koefisien kontingensi $\mathrm{C}$ yaitu 0,512 nilai tersebut menunjukkan hubungan yang sedang antara variabel sikap dengan kepadatan lalat.

Beberapa faktor yang mempengaruhi pembentukkan sikap seseorang terhadap suatu objek, diantaranya adalah sasaran komunikasi 
yang memiliki pengaruh besar dalam pembentukkan pendapat, konsep, dan kepercayaan atau keyakinan seseorang. Dilihat dari jenjang pendidikannya, responden yang tingkat pendidikan SD banyak memiliki sikap kurang baik, Menurut Schwartz (1992) dalam ${ }^{4}$, umumnya sikap adalah keyakinan yang di terjemahkan ke dalam tindakan pada objek yang diinginkan. Sikap yang tidak baik bisa disebabkan oleh kurangnya pengetahuan tentang pengolahan sampah yang baik. Hal ini sejalan dengan penelitian yang dilakukan oleh ${ }^{5}$ menyatakan informasi atau pengetahuan adalah syarat penting bagi sikap, jadi sikap bukan hanya perasaan mendukung atau tidak mendukung perilaku, namun juga menyangkut estimasi akan hasil dari perilaku tersebut. Sikap merupakan kesiapan untuk bereaksi terhadap objek dilingkungan tertentu sebagai suatu penghayatan terhadap objek dilingkungn tertentu sebagai suatu penghayatan terhadap objek. ${ }^{6}$
C. Hubungan tindakan pedagang dalam mengelola sampah dengan kepadatan lalat

Hasil penelitian terhadap tindakan pedagang dalam mengelola sampah dengan kepadatan lalat didapatkan bahwa pedagang yang memiliki tingkat tindakan yang kurang baik sebagian besar yaitu 56,3\% memiliki kepadatan lalat yang tinggi sedangkan pedagang yang memiliki tingkat pengetahuan yang baik semuanya yaitu $29,2 \%$ memiliki kepadatan lalat yang sedang. Kuat lemahnya hubungan dilihat dari koefisien kontingensi C yaitu 0,588, nilai tersebut menunjukkan hubungan yang sedang antara variabel tindakan dengan kepadatan lalat.

Menurut ${ }^{7}$, bentuk operasional tindakan dapat dikelompokkan menjadi tiga jenis yaitu tindakan dalam bentuk pengetahuan yaitu dengan mengetahui situasi atau merangsang dari luar, tindakan dalam bentuk sikap yaitu tanggapan batin terhadap keadaan atau rangsangan dari luar, tindakan dalam bentuk tindakan yang sudah kongkret, yaitu berupa perbuatan atau action terhadap situasi 
atau rangsang dari luar. Tindakan buruk responden disebabkan karena sebagian responden masih belum bertindak untuk mengelola sampah di tempat penjualan mereka. Menurut Enviromental Services Program (2011:19) dalam ${ }^{8}$ kunci keberhasilan program kebersihan dan pengelolaan sampah terletak pada pemilihan. Tindakan disebabkan oleh faktor predisposisi yaitu sikap keyakinan, nilai, motivasi, dan pengetahuan ${ }^{9}$ D. Kepadatan lalat

Kepadatan lalat dari 48 pengukuran didapatkan bahwa sebagian besar yaitu 27 pengukuran dengan persentase $56,3 \%$ memiliki kepadatan lalat yang tinggi, dan 21 pengukuran dengan persentase $43,8 \%$ memiliki kepadatan lalat sedang. Kepadatan lalat di Pasar Desa Adat Sembung timbul karena tempat yang disukai lalat yaitu sampah yang berserakan di sekitaran kios pedagang pedagang makanan, los penjualan buah ,sayur dan daging, sisa makanan dari hasil olahan yang berbau busuk, mengundang lalat untuk hinggap dan berkembangbiak.
Pengukuran kepadatan lalat dengan menggunakan fly grill didasarkan pada sifat lalat yang kecenderungan untuk hinggap pada tepi atau tempat yang bersudut tajam $^{9}$ Pengetahuan, sikap dan tindakan untuk mengelola sampah yang benar sebaiknya diterapkan agar dapat mengurangi populasi lalat yang ada di sekitar pasar yaitu dengan memperbaiki hygiene dan sanitasi lingkungan salah satunya yaitu menghilangkan tempat perindukan dengan cara mengangkut sampah yang berada di kontrainer setiap harinya agar tidak mengundang kerumunan lalat. Pengumpulan, pembuangan serta pengangkutan sampah dikelola dengan baik. Dalam penelitian ${ }^{10}$ Pengelolaan Sampah dapat dilakukan dengan menerapkan Konsep 3R (Reduce,Reuse,Recycle) Reduce merupakan aktivitas mengurangi timbulan sampah pada sumber sampah tersebut. 


\section{SIMPULAN}

Berdasarkan hasil penelitian Hubungan Tingkat Pengetahuan Sikap dan Tindakan Pedagang dalam Mengelola Sampah dengan Kepadatan Lalat di Pasar Desa Adat Sembung tahun 2020 dapat disimpulkan beberapa hal sebagai berikut :

1. Pengukuran tingkat pengetahuan dan sikap pedagang dalam Mengelola Sampah dengan Kepadatan Lalat ,bahwa pedagang yang memiliki tingkat pengetahuan dan sikap yang kurang baik yaitu $54,2 \%$ memiliki kepadatan lalat yang tinggi sedangkan pedagang yang memiliki tingkat pengetahuan yang baik yaitu 22,9\% dan sikap yg baik 25,0\% memiliki kepadatan lalat yang sedang.

2. Pengukuran tindakan pedagang dalam Mengelola Sampah dengan Kepadatan Lalat di Pasar Desa Adat Sembung pedagang yang memiliki tindakan yang kurang baik yaitu $56,3 \%$ memiliki kepadatan lalat yang tinggi sedangkan pedagang yang memiliki tindakan yang baik semuanya yaitu 29,2\% memiliki kepadatan lalat yang sedang.
Pengukuran tingkat kepadatan lalat di masing-masing 48 pengukuran didapatkan bahwa yaitu 27 pengukuran dengan persentase $56,3 \%$ memiliki kepadatan lalat yang tinggi, dan 21 pengukuran dengan persentase $43,8 \%$ memiliki kepadatan lalat sedang.

3. Analisis hubungan tingkat pengetahuan, sikap, dan tindakan pedagang dalam mengelola sampah dengan tingkat kepadatan lalat di Pasar Desa Adat Sembung menunjukkan hasil uji statistik menggunakan uji chi square diperoleh nilai $\mathrm{p}=0,000<\alpha(0,05)$ yang berarti Ho ditolak atau ada hubungan yang bermakna atau signifikan serta menunjukkan hubungan yang sedang antara variabel.

\section{SARAN}

1. Puskesmas yang terkait dengan pengendalian binatang pengganggu/vektor agar memberikan penyebaran informasi tentang vektor penularan penyakit khusunya lalat, serta memberikan 
penyuluhan tentang cara mengelola sampah yang baik.

2. Bagi seluruh pedagang disarankan langsung membuang sampah ke kontrainer dan tidak membiarkan sampah berserakan di sekitar tempat berjualan dan menyediakan tempat sampah di depan tempat berjualan.

3. Bagi pihak pengelola kebersihan pasar agar selalu memperhatikan lingkungan pasar seperti jadwal mengangkut sampah, memberikan sosialisasi dengan bekerjasama dengan puskesmas untuk memberikan pemahaman kepada pedagang bahwa menjaga lingkungan seperti mengelola sampah juga merupakan tanggung jawab bersama.

4. Bagi pengunjung pasar agar ikut bertindak dalam menjaga lingkungan pasar dengan cara tidak membuang sampah sembarangan agar terbebas dari bahaya yang dapat ditimbulkan oleh lalat.

\section{DAFTAR PUSTAKA}

1. Prayogo, S. Deskripsi Kepadatan Lalat Di Pasar Kota Banjarnegara Tahun 2015. Jur. Kesehat. Lingkung. 34, 124 223 (2015).

2. Yulianto, B. Partisipasi Pedagang Dalam Melakukan Pemilahan Sampah di Pasar Baru Kecamatan Tampan Kota Pekanbaru Participation Traders Separating Waste in Pasar Baru Tampan sub District Pekanbaru City. J. Kesehat. Komunitas 3, 69-72 (2016).

3. Riandes, R. Partisipasi Mahasiswa Fakultas Kedokteran Universitas Riau dalam Membuang Sampah pada Tempatnya di Lingkungan Kampus Fakultas Kedokteran Universitas Riau (Doctoral dissertation, Riau University). 1-14 (2016).

4. Palupi, T. Hubungan Antara Sikap Dengan Perilaku ProLingkungan Ditinjau dari Perspektif Theory Of Planned Behavior Relationship Between Attitude And Pro- 
Environmental Behavior from the Perspective of Theory of Planned Behavior Perilaku ProLingkungan. 14, 2015-2018 (2017).

5. Notoatmodjo. Promosi

Kesehatan \& Ilmu Prilaku. (2007).

6. Febriyanto, M. A. B. Hubungan Antara Pengetahuan Dan Sikap Dengan Perilaku Konsumsi Jajanan Sehat Di MI Sulaimaniyah Mojoagung Jombang. (2016).

7. Sulistiyorini, N. R., Darwis, R. S. \& Gutama, A. S. Partisipasi Masyarakat Dalam Pengelolaan Sampah Di Lingkungan Margaluyu Kelurahan Cicurug. Soc. Work J. (2015).

8. Hombing, windy oktavia boru. Peningkatan

Pengetahuan,Sikap,Dan

Tindakan Remaja Laki-Laki Di SMK Negeri 4 Kecamatan Umbulharjo Kota Yogyakarta Tentang Antibiotika Dengan Metode CBIA (Cara Belajar Insan Aktif). (2015).

9. Subagyo, A. Fly Density and
Identification Analysis and Control Efforts In Traditional Market Purwokerto Densitas dan Identifikasi Lalat serta Upaya Pengendaliannya di Pasar Tradisional Purwokerto Agus Subagyo Arif Widyanto Aris Santjaka Jurusan Teknik Radiodiagnosti. $\quad 483-491$ (2014).

10. Darmawan, A. Perilaku Masyarakat dalam Mengelola Sampah di Kota Bima Nusa Tenggara Barat. 10, 175-186 (2014). 